\title{
Landscapes of fear
}

Simone Tulumello

Universidade de Lisboa, Instituto de Ciências Sociais, Lisbon, Portugal.

This is the accepted version of the manuscript:

Tulumello, S., 2020. Landscapes of Fear. In: Kobayashi, A. (Ed.), International Encyclopedia of Human Geography, 2nd edition. vol. 8, Elsevier, pp. 127-130. https://dx.doi.org/10.1016/B978-0-08-102295-5.10277-X

\section{Keywords}

Urban fear, fear of crime, fear of violence, feelings of safety, urban security, urban geopolitics, urban political economies, power, affect, otherness, urban space, feminist geography, critical urban studies, feelings and emotions.

\section{Abstract}

Fear is among the most powerful of human feelings. Urban fear, the fear of being victims of crime and violence in urban space, particularly so. Urban fear shapes space and is in turn shaped by space. The relationship between fear and space has been studied in terms of three key dimensions: urban (geo)politics, or the political economies of security; otherness, the way social cleavages (e.g., race/ethnicity, gender, class, sexuality) mediate the encounter in urban space; and space, the role of the built environment and (modernist) spatialities and urban planning. In line with the recent affective turn in social and cultural geography, the concept of landscapes of fear has provided a fruitful theoretical instrument to understand the co-constitution of emotions and practices in this field. By connecting the dimensions of (geo)politics, otherness, and space, the mobilization of the concept of landscape has allowed understanding how context-specific, yet trans-scalar, atmospheres of fear are (re)produced at the intersection of politicaleconomic, socio-cultural, and technical factors. 


\section{Glossary}

Crime $A$ behavior, action, or practice in violation of a legal code. With the exception of few actions universally considered criminal (e.g., homicide), most crimes are above all politically, socially, culturally, and geographically dependent constructions.

Discourses of fear Discourses and texts (e.g., political speeches, media reports, fictional narratives) about crime and violence rhetorically used to boost fear of crime and violence.

Environmental crime prevention A set of spatial devices and tactics designed with the goal of lowering crime in urban spaces.

Fear of crime and violence A complex feeling that is not only related to actual risks of victimization, but also to external influences (e.g., discourses of fear), personal attributes (e.g., one's gender, age, racial/ethnicity, class), and group perceptions.

Reported crimes Crimes known to the police and the judiciary, used to calculate official crime rates. Reported crimes, with few exceptions, represent only a part of the phenomena of crime and violence-for instance, because they are framed through the legal definitions of crime and cannot account for unreported crimes - and should thus always be interpreted with caution.

Urban geopolitics An approach to the understanding of urban transformation through geopolitical lenses.

Urban fear The fear of crime and violence as experienced in, and with regard to, urban spaces.

Victimization Victimization (and victim) can refer to a number of dimensions related to crime, violence, and other forms of coercion. In this entry, it refers to the individual experience of having been exposed to a crime.

Fear holds a special place among human feelings. It is a deeply ambivalent feeling: necessary to our survival, fear can also make life extremely difficult- 
e.g., many mental health challenges are expressed through feelings and emotions of fear and anxiety. By shaping our spatial perceptions, urban fear influences the way we navigate the city and the construction of personal geographies. Fear, and especially urban fear, is powerful. Indeed, media, politicians, and corporations have used discourses of fear to shape perceptions of public priorities, needs, and "emergencies."

It is therefore no surprise that the relations between fear and (urban) space have become a rich field of academic interest. For a long time, the dominant approach has been to research spatial solutions to security problems (for instance, so-called environmental techniques for crime prevention), assuming, from a deterministic perspective, that reducing crime in urban space would automatically reduce people's fear. The relation between crime rates and urban fear, however, has been shown to be quite problematic, and assumptions of direct causality tend to be inaccurate: urban fear rarely correlates with actual risks of victimization. Moreover, we have witnessed during the last few decades spectacular growth in expressions of urban fear, particularly in Western societies which are overall relatively safe. Of course, safety is not equally shared and victimization is shaped by divides of all sorts.

A small but growing body of scholarship has focused on fear as a lens to explore critically the intersections of space, culture, and politics, and processes of urban segmentation, exclusion, and injustice. This endeavor has been pursued by drawing on, and intersecting, many academic traditions (e.g., Marxist, feminist, post-colonial), theoretical lenses, and epistemological perspectives. In particular, recent developments in social and cultural geography have advocated an exploration of the way feelings and emotions are entangled with affect-affect being understood as the medium through which human beings enter into relation with the materiality of the world, and feelings and emotions being manifestations of affect. Addressing affect involves focusing on the co-constitution of practices and emotions. It is also important to consider the ways affect has "power-to," following Brian Massumi-for instance, power to change the order of things, a complementary understanding to the conception of "power-over," over other subjects or entities. Thinking affect helps to develop an understanding of power beyond its tangible expressions. 
The concept of "landscapes of fear" (or "fearscapes") - that departs from and problematizes the idea of "spaces of fear" - is particularly attuned to the affective turn in geography. The concept of landscape has a long history in cultural geography, where its traditional understanding-linked to the representation of nature-has been articulated with philosophical, social, and political dimensions. Landscape refers to a network of relationships between the subject, representation, embodied experiences, and sociopolitical factors. In this way, landscape helps articulating the many dimensions necessary to conceptualize fear and/in/through space.

Yi-fu Tuan introduced the concept of landscapes of fear to cultural geography with the goal of putting psychological states and tangible environments into dialogue. Tuan developed a socio-spatial understanding of urban fear that addresses how environments that were created as a means of protection (cities) had become disorderly, and fearful, labyrinths. There are similarities here with classical accounts of the urban experience by George Simmel or Henri Laborit, who reflected on the massive urbanization of Europe following the industrial revolution and considered anomie and aggressiveness inevitable consequences of human coexistence in densely populated environments. These approaches have indeed helped taking fear seriously as a crucial component of the production of individual's and groups' worldviews. However, they fail to grasp the political dimensions that may be behind and beyond the production of fear itself.

John Gold and Jorge Revill have further developed the concept of landscapes of fear, by focusing on the way fear, though often irrational from the perspective of the individual, is often a production of (capitalist and racist) rationalities. Gold and Revill's work suggests that a focus on landscapes of fear can help balance between critical discussion of fear as a matter of political economy (as suggested by Leonie Sandercock) and the theorization of actually existing urban fear.

Discussions in this field have been developed around three dimensions (a systematization inspired by Hazem Abu-Orf's theory on fear in cities in conflict): the urban (geo)politics of fear; the role of fear in shaping the encounter with otherness; and the role of the built environment (and its dominant spatialities) in shaping personal feelings. The concept of landscapes 
of fear can be mobilized to intersect, and move beyond, these three dimensions. A caveat, as my research been carried out in Western contexts (Southern Europe and the South of the USA), my perspective is inevitably biased toward the situated experiences of these places - and I am better positioned to provide examples by reflecting on the trajectories of Western urbanization. This article, in short, is "placed" but can hopefully provide theoretical tools useful to address the intersection between fear and space beyond the sites where it was developed.

\section{(Geo)politics}

Focusing on the urban geopolitics of fear means considering fear as something more than an inherent component of urban life. This approach involves exploring the political economic dimensions of urban fear. Fear has often been used as an instrument of power. Public anxieties and dramas of many sorts have long been used to shape public attention and this has become more and more true during recent decades.

Daniel Goldstein has suggested that we live in a "security moment" when security has become an instrument of government and a central component of political debates. This trend has been intertwined with wider social and political transformations, in Western countries epitomized by the decline of the post-second-world-war welfarist consensus and the hegemony of neoliberal governmentalities. Though crime and violence have been steadily decreasing almost everywhere in the West since the 1980s, they have been used to shape more and more fields of public interest, with an acceleration since major terrorist attacks in New York, London, Madrid, and Mumbai amongst other cities in the early 2000s. There is a trend towards securitization that has been particularly evident in the USA-with the socalled "wars" on drugs, crime, and terrorism-but have been evident in different forms in a range of contexts. For instance, in Italy the security/immigration nexus has been, since the 1990s and especially in the late 2000s and 2010s, the central argument used for restructuring national politics by pushing toward repression and away from social policy. 
The political use of fear helps us make sense of how significant political and policy transformations have been supported by vast majorities in public opinions. In liberal democratic contexts, where building consensus is crucial to government, feelings and emotions can play a decisive role in the shaping of political agendas. Conservative politicians in particular have discovered that "crime pays" in terms of political support and they have often presented themselves as "tough on crime" (and terrorism). In turn, the entire political spectrum has shifted increasingly toward security both nationally and locally. In many countries and cities, for example, the most repressive measures have been approved by "tough on crime" center-left, social-democratic parties-e.g., Clinton's 1994 Crime Bill (USA) or Minniti and Orlando's 2017 immigration law reform (Italy).

From the perspective of (geo)politics, fear been used as an instrument for building political consensus. Fear has also been a central component of the progressive governmentalization of urban space, as Ugo Rossi and Alberto Vanolo suggested. The political economies of fear have been an instrument to justify a wide set of urban policies (e.g., fortification, surveillance) exposed by urban political geography scholarship such as Stephen Graham's discussion of the way state apparatuses have been increasingly framing the urban terrain as a conflict zone.

\section{Otherness}

Rachel Pain has argued that relying on a purely "globalized" understanding of fear risks neglecting the role of emotional topographies in the making of space and place. On the contrary, focusing on otherness means exploring the way fear mediates daily encounters in urban space. Feminist scholarship has emphasized the role of feelings in the construction of individual and collective geographies. As public space is often characterized by considerable diversity, navigating the city also means encountering otherness. The urban encounter is a complex experience, characterized by possibilities and ambiguities, and a variety of possible emotions, ranging from curiosity and attraction all the way to concern and fear. Navigating urban otherness has been described as an experience of boundary crossing, where one's own 
identity is continuously (re)constructed in relation with and in opposition to others' identities and behaviors. Importantly, this experience of being-inspace is mediated by a number of dimensions. According to Elizabeth Grosz, it is the very functioning of (different) bodies that transform understandings of space and time.

Group differences associated with gender, race/ethnicity, class, sexuality, and age also matter. When an individual encounters another individual, their perception of that encounter will be shaped by assumptions and representations associated with the visible characteristics of the other. Hegemonic normative constructions of social groups hence become significant in experiences of fear. Such constructions are also intersectional in nature as evident in the generalized representation of women as potential victims of violent crime, and especially sexual violence, in public space. In general, we know that women tend to be victims of violent crime less than men in public spaces, where they tend to experience more often noncriminalized aggressive behaviors, like harassment-but see Carina Listerborn's accounts of gendered and Islamophobic violence in Sweden and its role in establishing and maintaining hegemonic spatial and political orders.

Sexual violence, as feminists have long claimed, happens mainly within private spaces, especially the home. While the image of the racialized, classed, or medicalized (black/brown/immigrant/poor/mentally ill) rapist of (white) women is a ubiquitous topos of public representation, we know that sexual violence is more often committed by acquaintances, (ex-)partners, or relatives. As such, the mainstream equalization of sexual crime with otherness in public space (re)produces a patriarchal social order-the need to protect the woman-reinforced by fears of the racialized other. On the one hand, this fear is a powerful instrument to constraining women's mobility by discouraging them to circulate alone, particularly in certain places and at certain times. On the other hand, this fear is part and parcel of the enforcement of racial cleavages and production of differentiated citizenships-see, for instance, Alexandra Hall's discussion of the role of fear and race in the production of deportable subjects in UK detention centers. These are just some examples of the manifold ways through which urban fear mediates the encounter with otherness, becoming a component of the 
politics of intersectional difference that is located in between hegemonic (geo)politics, and local and individual geographies.

\section{Spaces}

Focusing on space means exploring the role of the built environment in mediating urban fear. This involves moving from a discussion about fear-inthe-city, toward one about fear-through-the-city. This discussion has long been central to urban politics. For instance, public lighting became a topic of public discussion since the panics created by Jack the Ripper and surrounding narratives. The fear/space nexus has been at the core of research on the relationship between spatial form and emotions - an endeavor of much architectural and urban morphology research (for instance works carried out from the perspective of space syntax). These endeavors, however, by seeking deterministic relationships between space and feelings, have not been capable of unravelling the ways space and the built environment-and with them urban planning and policy-intersect with the dimensions of (geo)politics and otherness.

In particular, in the context of European and North American cities, modernist forms of urban planning have played a crucial role in shaping urban spaces of fear. In these regions of the world, the urban fabric produced since the early $20^{\text {th }}$ century is largely dominated by private automobility and road infrastructures, functional segregation due to land-use zoning, and the subsequent spatial dispersion of residential, labor, and leisure activities. In contrast to the dominance of pedestrian mobility and the functional mix of the pre-industrial city, the modernist city is one where the encounter is less and less frequent. In addition to this, spatial segregation along the lines of race/ethnicity and class is common and further reduces the possibility of encounter with otherness-this holds particularly true in Northern American cities. The result is that encounters with others are often an unusual and hence possibly frightful experience.

At the same time, the discipline of planning was itself established as a response to a number of fears - fear of disorder and revolt, and the fear of the long-term effects of disorganized urbanization over the health of working 
classes. Baron von Haussmann's plans for Paris in the $19^{\text {th }}$ century, included among the first "modernist" examples of urban renovation, are the quintessential example here. By cutting large avenues through the dense urban fabric of the city, Haussmann made it much harder for revolutionaries to erect barricades, which had been a crucial tactic for urban revolts of the revolutionary period, at the same time as easing the dislocation of the army throughout the city.

More recently, discourses of fear have been mobilized as part of a series of spatial "solutions" that are claimed to reduce insecurity. These new spatialities pertain to four categories: Enclosures, the spaces of forced exclusion for allegedly dangerous groups (epitomized by the form of the camp, as discussed by Claudio Minca) and the space of auto-seclusion chosen by affluent groups (quintessentially, fortified residential compounds like gated communities); Post-public Space, the production of privately owned, collective spaces advertised as "safe" (quintessentially, the shopping mall) and the fortification and privatization of public spaces and buildings; Barrier, the use of infrastructures to fragment the urban space and segregate "marginal" urban areas; and Control, the proliferation of surveillance devices such as CCTVs. These emerging spatialities increase social cleavages among those who have access to the most desirable spaces and those forced into camps and similar forms. But, as Dora Epstein suggested, the process of labelling some particular spaces as "safe" reinforces the idea that the urban space in general is dangerous, a place to be protected from. In a similar vein, Andrea Mubi Brighenti and Andrea Pavoni have shown that fear and stress can be produced by the very efforts at making the city a "comfortable" place.

These examples suggest that planning and urban design have a role to play in pushing the urban encounter toward curiosity or fear. This role, however, cannot be considered an independent "variable" - like determinist spatial analysis and interventions do. Rather, it is the articulation of the dimensions outlined here that should be explored and taken into account, for which the concept of landscape is particularly useful. 


\section{Scapes}

The (re)production of urban fear is a complex process where political economic (e.g., the political use of fear), socio-cultural (e.g., personal and collective geographies), and spatial dimensions interact at the intersection of (geo)politics, otherness, and space. There are a number of paradoxes or contradictions of fear that characterize its (re)production. These include the evidence that the most fearful (individuals, groups, societies) are not often the most in danger, all the way toward the systematic failure of technical devices or strategies in increasing feelings of safety. There are also vertical/hegemonic dimensions beyond the omnipresence of paradoxes of fear where fear is deployed as a kind of governmentality. The use of terrorism as a discursive device for the militarization of global cities is a case in point. These discourses and their materialization in changing urban form interact with the paradoxes listed above, producing fear as a technical, sociocultural, and emotional phenomenon.

So, how can we theoretically think and understand the paradoxes of urban fear? Are they really paradoxes, or do they signal that fear is, beyond a feeling, a complex construction where the environment (politics, policies, specific social and cultural atmospheres) plays a bigger role than what is the purported source of fear itself (i.e., crime and violence)? In line with recent geographic scholarship on affect, fear can be understood as the product of violence-that-looms, that can be actualized, be it criminal violence, the political and discursive production of it, or structural violence. It is at this intersection that the concept of landscape provides a framework for a dialogue among the different dimensions surrounding urban fear.

Landscape comes from the Dutch word composed of land and scap (condition). It was originally used to define a painting representing a wide view of a natural environment and was later used to refer to the extensive meaning of a tract of land with its characteristics. In a sense, landscape can only exist at a distance: it exists because of the distance between the observer and the observed. This idea comes into use to think fear as an affect (beyond a feeling). Indeed, urban fear is generated by a number of "distances", beyond any direct experience of crime or violence, by geopolitical constructions, stereotypical characterizations, and urban 
spatialities - fear is a relational construction. Fear "affects" at a distance, by shaping spaces before any actualization (of crime, of violence). As such, thinking urban fear means, above all, understanding how context-specific, yet trans-scalar (at the same time global and localized), atmospheres are constructed by the production of "distances" that have political-economic, socio-cultural, and technical nature.

What happens when the distance generating the landscape is reduced? At the same time landscape is lived and dissolves (it becomes place). Similarly, by reducing the distance, by crossing social and spatial boundaries, urban fear is experienced and at the same time overcome-again, the complex, ambivalent, and paradoxical nature of (urban) fear. Only by living urban space, and being conscious of the multiplex dimensions of fear, can we find they are not so frightful and, at the same time, how inevitable, and even productive, their frightfulness is.

\section{Acknowledgements}

I am grateful to Francesca Esposito and Andrea Pavoni, and Francis Collins for constructive critique and insightful comments.

\section{Further readings}

Abu-Orf, H. (2013). Fear of difference: "Space of risk" and anxiety in violent settings. Planning Theory 12, 158-176.

Brighenti, A. M. and Pavoni, A. (2017). City of unpleasant feelings. Stress, comfort and animosity in urban life. Social and Cultural Geography, online first, DOI: 10.1080/14649365.2017.1355065.

Epstein, D. (1998). Afraid/not: Psychoanalytic directions for an insurgent planning history. In Sandercock, L. (ed.) Making the invisible visible: A multicultural planning history, pp. 209-226. Berkeley: University of California Press.

Evans, B. (2017). Histories of violence: Affect, power, violence - The political is not personal. Brad Evans interviews Brian Massumi. Los Angeles Review of 
Books, 13 November, https://lareviewofbooks.org/article/histories-ofviolence-affect-power-violence-the-political-is-not-personal/\#.

Gold, J. R., and Revill, G. (2003). Exploring landscapes of fear: Marginality, spectacle and surveillance. Capital and Class 27, 27-50.

Goldstein, D. M. (2010). Toward a critical anthropology of security. Current Anthropology 51, 487-517.

Graham, S. (2010). Cities under siege: The new military urbanism. New York: Verso.

Grosz, E. (1995). Space, time, and perversion. Essays on the politics of bodies. New York: Routledge.

Hall, A. (2010). "These people could be anyone": Fear, contempt (and empathy) in a British immigration removal centre. Journal of Ethnic and Migration Studies 36, 881-898.

Listerborn, C. (2015). Geographies of the veil: Violent encounters in urban public spaces in Malmö. Social and Cultural Geography 16, 95-115.

Minca, C. (2015). Geographies of the camp. Political Geography 49, 74-83.

Pain, R. (2009). Globalized fear? Towards an emotional geopolitics. Progress in Human Geography 33, 466-486.

Rossi, U. and Vanolo, A. (2012 [2010]). Urban political geographies. A global perspective. London: Sage.

Sandercock, L. (2002). Difference, fear, and habitus: A political economy of urban fear. Urbanistica 119, 8-19.

Tuan, Y. (1979). Landscapes of fear. Oxford: Basil Blackwell.

Tulumello, S. (2017). Fear, space and urban planning: A critical perspective from Southern Europe. Cham: Springer. 


\section{Cross References}

Affect; Crime Geography; Criminalization; Critical Geography; Ethnic Conflict; Feminism/Feminist Geography; Gated Communities; Governmentality; Multicultural City; Neoliberalism, Urban; Race; Society-Space; Surveillance; Violence.

\section{Bio}

Simone Tulumello is a research fellow at the University of Lisbon, Institute of Social Sciences, since 2013. In 2016, he has been Fulbright Research Scholar at the University of Memphis and afterwards Policy Fellow at the Benjamin L. Hooks Institute for Social Change. His research interests lie at the border between human geography, planning research and critical urban studies: urban security and safety; urban fear and planning; housing policy; crisis, austerity and neoliberal urban policy; Southern European and Southern US cities. His first monograph, Fear, Space and Urban Planning: A Critical Perspective from Southern Europe, was published in 2017 by Springer. 